\title{
ALIGNING BUSINESS AND IT STRATEGIES IN BANKING: A CASE STUDY
}

\author{
Ayfer BASAR \\ Istanbul Technical University,Turkey
}

\begin{abstract}
Determining appropriate business and information technology (IT) strategies supporting each other is fundamental in terms of achieving IT flexibility and business value. Although IT organizations appreciate the importance of the strategic alignment between IT and business as a result of rapid changes in increasing competition, they need to learn the ways of aligning the strategies and establishing an efficient roadmap. This study proposes a generic methodology to build an effective IT roadmap. For this aim, business and IT strategies are aligned in the first step. Then, IT strategies and service areas are aligned based on the improvements in the technology and customer requirements. Expert judgments are considered and Analytical Hierarchy Process (AHP) is applied for alignment, such that relative weights of business-IT strategies and services areas are obtained. The methodology is implemented in an IT company of a Turkish bank. The results are appreciated by the senior managers of the company.
\end{abstract}

Keywords: Business strategy, information technology, strategic alignment, decision making, AHP, case study.

\section{INTRODUCTION}

Strategy is described as the planned actions taken by the management in order to attract, obtain, keep and satisfy the customers for the successful competition (Thompson et al. 2007). IT is a significant capital investment since it provides external and internal business support for companies. IT helps businesses to create value in their products and services. The capacity of the organizations to compete depends on how they combine their strategies and IT resources (Boaden, 2006; Gordon et al., 2008).

In the past, IT is undertaken simply as a technology to apply business goals, and IT roadmaps mostly focused on tactical business requirements which were tangible instead of enterprise strategy. Thus, IT investments were determined according to the short-term needs rather than increasing business value for a long-term period (Burgelman et al., 2001). In the present, IT encourages intensively to the development of efficient business strategies and high earnings, and companies require IT to support their business objectives to get the competitive advantage, continual growth, and organizational efficiency. Therefore, achieving business strategies without the usage of IT is almost impossible. Furthermore, incorporating innovation and flexibility into the business processes by using IT has become inevitable for the organizations (Sambamurthy et al., 2003). IT is strategically used especially in the banking sector due to the necessity for high technology in competitive environment (Brady and Targett, 2007). On the other hand, the relationship between IT and business strategies is not fluent still. Traditionally, the literature about strategic alignment mostly addresses that IT strategies are determined by business strategies (Sabherwal et al., 2001; Kearns and Lederer, 2003; Chan and Reich, 2007). However, it is stated that IT strategies give direction to the business strategies in other studies (Henderson and Venkatraman, 1999). This means that, although there are many studies discussing strategic alignment, there is no agreement regarding the appropriate techniques to align business-IT strategies and establish a roadmap based on aligned strategies (Masa'deh, 2012; Coltman et al., 2013). In fact, earlier studies in the literature are lack of experimental support (Baets, 1992; Papp, 1995; Masa'deh, 2012; Coltman et al., 2013). It is accepted that the gap about strategic alignment brings about low profitability, efficiency, and performance in companies. For this reason, a methodology is required to achieve strategic fit between business and IT, since all companies have to align its business and IT strategies to survive in today's competitive environment.

This study proposes a decision support methodology (AHP) to align strategies and prepare an efficient IT roadmap which is based on expert judgments. AHP originally developed by Saaty (1980) is the most common method in the literature about decision making. It is widely implied for obtaining weights of the criteria and alternatives for a variety of research fields and has been implemented in a wide range of 
studies for many years (Yoon, 2005; Wang et al., 2013; Kutlu et al., 2014; Longaray et al., 2015; Karim and Karmaker, 2016; Tasci and Gorener, 2016; El Haji et al., 2017).

The remaining sections of the paper are organized as follows: Authors present research related to business-IT strategies and strategic alignment in Section 2. Section 3 is dedicated to the proposed AHP method to find the relative priorities of business-IT strategies and service areas. Authors provide an application of the proposed method in a Turkish IT company in Section 4. Finally, conclusions and further research are presented in Section 5.

\section{BUSINESS - IT STRATEGIES AND ALIGNMENT}

Business strategy is defined as the long-term plan of organizations in order to achieve a goal related to the business. It incorporates defining the objectives and extensions of the activities by considering the environment and nature of the business, customer properties, and competition in the market (Zahra and Covin, 1993). Alignment between business and IT strategies has been undertaken as an important issue in both academic and professional environment for many years. Many studies have been carried out especially in the recent past since researchers and IT executives consider the issue significant (Chiang and Nunez, 2013; Coltman et al., 2013; Wagner et al., 2014).

Strategic alignment has been defined differently by the researchers. For instance, Kanellis et al. (1999) discussed alignment as the balance between an enterprise and its strategy, processes, environment, and technology. Reich and Benbasat (1999) and Walter et al. (2013) described alignment as the size of the fit among IT mission, goals, and plans. The relationship between business and IT strategies has been ignored and it is assumed that alignment is implied in case business strategies determine IT strategy for many years (Miller, 1993; Sabherwal et al., 2001; Kearns and Lederer, 2003; Chan and Reich, 2007; Tarhini et al., 2013). However, it is also claimed that IT strategies can give direction to the business strategies which means IT plays an important role in terms of organization's business strategies and their applications (Henderson and Venkatraman, 1999). Huang (2009) emphasized the importance of IT functions' flexibility to reinforce strategic alignment and innovation capability of organizations. Chan et al. (2006), Chan and Reich (2007) and Torres et al. (2012) claimed that strategic alignment directly affect organizations' performance and return on the technological investments. Brodbeck et al. (2009) claimed that a series of factor (i.e., communication, architectural content, skills etc.) impact strategic alignment considerably.

Henderson and Venkatraman (1993) presented Strategic Alignment Model (SAM) which defines alignment with external and internal domains. There are totally four domains (business strategy, information system strategy, business infrastructure and processes, information systems infrastructure and processes) each including scope, competencies, processes, skills, infrastructure, and governance. SAM proposes that all these components have to be in sync in order to improve alignment. Labovitz and Rosansky (1997) proposed alignment with two dimensions as vertical and horizontal. The vertical dimension is concerned with the organization, and its capabilities, resources, people, strategy. The horizontal dimension involves the processes that the organization utilizes for value creation. Strategies are aligned by following the same direction and sharing the purpose which allows the integration of all resources and capabilities around the central goal. Luftman (2001) extended SAM model and suggested that senior executive support for IT, business - IT partnership, IT involved in strategy development, IT understanding the business, well-prioritized IT projects, and IT's leadership as enablers in strategic alignment. On the contrary, lack of support for IT and understanding the business etc. were described as inhibitors of strategic alignment. DeLone and McLean (2002) established an Information Systems Success Model for the strategic alignment in IT including three hypotheses. i) Quality of information systems, system and information affect positively the usage of the system and improves customer satisfaction. ii) Usage of the system and customer satisfaction affect each other and improve net benefits. iii) The net benefit has positive effect on the usage of the system and customer satisfaction.

Moreover, Lankhorst (2005) proposed Enterprise Architecture (EA) as a framework including principles, models, and methods used while designing and realizing the organizational structure, business processes, and information systems of an enterprise. The popularity of EA has increased by the study of Zachman (1987). Among a large number of EA frameworks in the literature, the most common ones are the Zachman (2003) and TOGAF (2011). These frameworks address the organization architecture models with the matrix and the layered approaches. TOGAF Framework distinguishes three layers which are business, information systems and infrastructure. Zachman Framework organizes the models in a matrix. 
Consequently, although strategic alignment is widely discussed in the literature, there is no method accepted to align business - IT strategies and related service areas in the literature (Bergeron et al., 2004; Chan and Reich, 2007).Therefore, it is required to propose an approach to fit business-IT strategies and service areas, and establish an efficient roadmap.

\section{AHP METHOD}

Problems about strategic alignment can be modeled by defining a decision goal, which is mapping the business and IT strategies in the most efficient manner by using the strategies predefined. It is clear that decision makers are generally more coherent when they compare different factors relatively in comparison with evaluating only one criterion. Therefore, AHP which is based on assessing only two factors at each time is the most efficient method among many weighting techniques (i.e., Rating, Ranking, Point Allocation, and Trade-off) (Malczewski, 1999). Saaty (1990) claimed that AHP method may provide efficient solutions transparently by analyzing the decision both in a qualitative and quantitative manner, and testing the consistency of the decision in a short time. Moreover, decision makers who evaluate the factors are generally selected among the experts in the related area and present their judgments without being impressed by any external drivers while using AHP (Badri, 2001). Therefore, AHP is found an effective technique for evaluating relative importance values of multi-criteria by expert evaluations. The method is applied as follows:

The hierarchy, involving a goal (i.e., strategic alignment), criteria (i.e., business strategies), and sub criteria (i.e., IT strategies, service areas), is constructed to collect expert judgments in pairs on the elements of the hierarchy with respect to the decision goal. A sample of a decision hierarchy is shown in Figure 1.

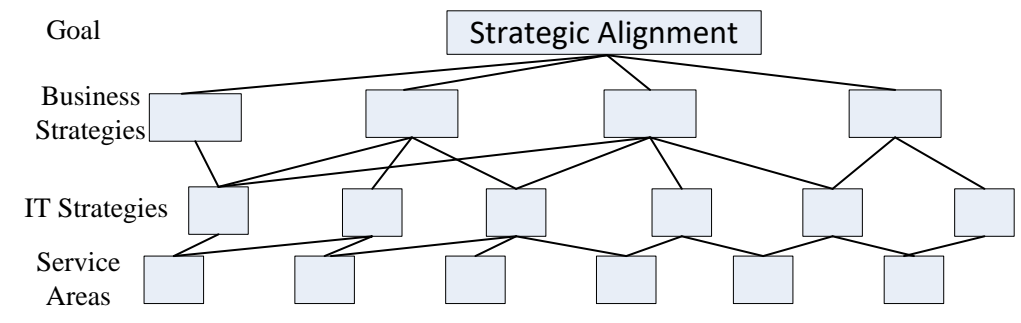

Figure 1: A Sample of Decision Hierarchy

Based on pairwise comparisons, a matrix $(A)$ is established to determine the weights of all factors relatively. In matrix $A, a_{i i}=1$ and $a_{i j}=1 / a_{j i}$ for $i, j=1,2, \ldots, n$. Let $C_{1}, C_{2}, \ldots, C_{\mathrm{n}}$ represent the set of business strategies, while $a_{i j}$ shows the judgment on each business strategy $C_{i}$ and $C_{j}$ and. The relative weight of two strategies is found by using the scale which is based on linguistic comparisons and developed by Saaty (1990). This scale which yields a $n \times n$ pairwise matrix $A$ is given in Table 1 .

$$
A=\left[a_{i j}\right]=\begin{gathered}
C_{1} \\
C_{2} \\
\vdots \\
C_{n}
\end{gathered}\left[\begin{array}{cccc}
1 & a_{12} & \cdots & a_{1 n} \\
1 / a_{12} & 1 & \cdots & a_{2 n} \\
\vdots & \vdots & \ddots & \vdots \\
1 / a_{1 n} & 1 / a_{2 n} & \cdots & 1
\end{array}\right] .
$$

Table 1: Scale Used in Pairwise Comparison in AHP

\begin{tabular}{ll} 
Importance & Definition \\
\hline 1 & Equal \\
3 & Moderate \\
5 & Strong or essential \\
7 & Very strong \\
9 & Extreme \\
$2,4,6,8$ & Intermediate values \\
\hline
\end{tabular}


The weights of the individual strategies are calculated by normalizing matrix $A$. For this aim, each entry of $A$ is divided by the sum of the related column. Then, the average of each row of the new matrix is calculated in order to find the weights of each strategy. Since the weights are already normalized; their summation is equal to 1 .

\section{STRATEGIC ALIGNMENT IN A TURKISH IT COMPANY}

Strategic alignment problems can be defined by a hierarchy involving the goal, which is aligning the business-IT strategies and IT strategies-service areas. Thus, the proposed AHP method is applied to the strategic alignment problem of an IT company in Turkey which has 682 employees working on the requirements of a Turkish national bank. In this case, the bank is the owner of the business requirements and strategies, while the company is responsible for defining its IT strategies along with the bank and supporting the bank to realize business strategies by making investments in the service areas. Business-IT strategies and service areas defined by the senior managers working in the bank and IT company together by considering competition in the financial market, technological improvements, and market research are given in Table 2.

Table 2: Business - IT Strategies and Service Areas

\begin{tabular}{|c|c|c|}
\hline Business Strategies & IT Strategies & Service Areas \\
\hline - Establishing efficient decision & $\begin{array}{l}\text { - Transformation in the customer } \\
\text { oriented digital channel }\left(I T S_{1}\right)\end{array}$ & - $\quad$ Channels $\left(S A_{1}\right)$ \\
\hline $\begin{array}{l}\text { Developing agile processes } \\
\left(B S_{2}\right)\end{array}$ & $\begin{array}{l}\text { - Customer oriented application } \\
\text { development }\left(I T S_{2}\right)\end{array}$ & $\begin{array}{l}\text { - Automation in branches } \\
\left(\mathrm{SA}_{2}\right)\end{array}$ \\
\hline $\begin{array}{ll}- & \text { Providing modern } \\
& \text { infrastructures }\left(B S_{3}\right)\end{array}$ & $\begin{array}{l}\text { - Service continuity with the } \\
\text { environmentally friend } \\
\text { applications }\left(I T S_{3}\right)\end{array}$ & $\begin{array}{l}\text { External systems and } \\
\text { business applications }\left(S A_{3}\right)\end{array}$ \\
\hline $\begin{array}{l}\text { - Integrating with the international } \\
\text { financial structure }\left(B S_{4}\right)\end{array}$ & $\begin{array}{l}\text { with the other organizations } \\
\left(I T S_{4}\right)\end{array}$ & - $\quad$ Analytic applications $\left(S A_{4}\right)$ \\
\hline & 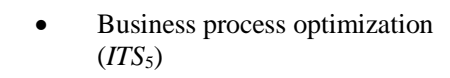 & $\begin{array}{l}\text { - System infrastructure, data } \\
\text { center and security }\left(S A_{5}\right)\end{array}$ \\
\hline & $\begin{array}{l}\text { Innovative, productive and } \\
\text { reliable service }\left(I T S_{6}\right)\end{array}$ & - $\quad$ Supporting applications $\left(S A_{6}\right)$ \\
\hline
\end{tabular}

\section{The hierarchy, involving the goal, business-IT strategies and service areas is constructed as given in Figure 2.}
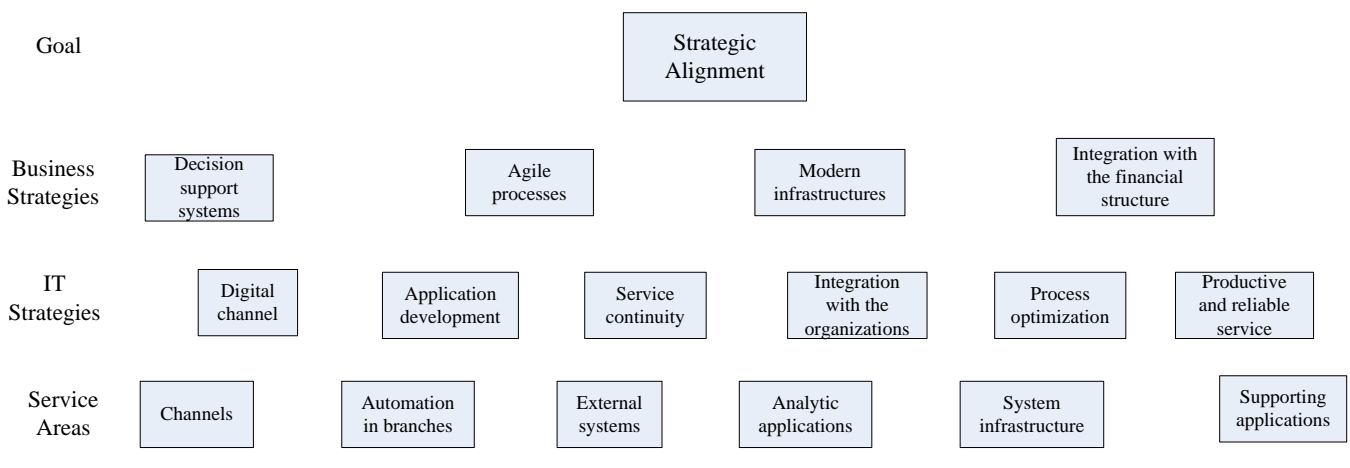

Figure 2: The Decision Hierarchy of the Strategic Alignment Problem

Alignment between business - IT strategies and service areas is provided by AHP method which is applied by expert judgments. For this aim, firstly, judgments of 10 experts ( 5 each working as senior managers in the bank and IT company) were collected through one-to-one meetings by a questionnaire in order to align the strategies and service areas. Authors asked the experts to give their opinion on the relative importance of business-IT strategy and IT-strategy-service areas one by one. In order to apply AHP method, totally eleven pairwise comparison matrices were constructed by each expert: One for four business strategies in the first level, four for six IT strategies in the second level to determine their weight on each business strategy, and six for six service areas to find their importance on each IT strategy. The evaluations of 10 experts were collaborated by the geometric mean in order to prevent the impact of the 
Journal of Global Strategic Management | V. 12 | N. 1 | 2018-June | isma.info | 005-016 | DOI: 10.20460/JGSM.2018.256 number of decision makers on the results. Expert judgments on business strategies as the first assessment among eleven evaluations are given in Table 3 .

Table 3: Pairwise Comparisons for Business Strategies

\begin{tabular}{|c|c|c|c|c|}
\hline Expert 1 & $\boldsymbol{B} \boldsymbol{S}_{\mathbf{1}}$ & $\boldsymbol{B} \boldsymbol{S}_{\mathbf{2}}$ & $\boldsymbol{B} \boldsymbol{S}_{\mathbf{3}}$ & $\boldsymbol{B} \boldsymbol{S}_{\mathbf{4}}$ \\
\hline $\boldsymbol{B} \boldsymbol{S}_{\mathbf{1}}$ & 1 & 3 & 5 & 5 \\
\hline $\boldsymbol{B} \boldsymbol{S}_{\mathbf{2}}$ & 0.33 & 1 & 0.33 & 2 \\
\hline $\boldsymbol{B} \boldsymbol{S}_{\mathbf{3}}$ & 0.2 & 3 & 1 & 7 \\
\hline $\boldsymbol{B} \boldsymbol{S}_{\mathbf{4}}$ & 0.2 & 5 & 0.14 & 1 \\
\hline
\end{tabular}

\begin{tabular}{|c|c|c|c|c|}
\hline Expert 2 & $\boldsymbol{B} \boldsymbol{S}_{\mathbf{1}}$ & $\boldsymbol{B} \boldsymbol{S}_{\mathbf{2}}$ & $\boldsymbol{B} \boldsymbol{S}_{\mathbf{3}}$ & $\boldsymbol{B} \boldsymbol{S}_{\mathbf{4}}$ \\
\hline $\boldsymbol{B} \boldsymbol{S}_{\mathbf{1}}$ & 1 & 5 & 3 & 3 \\
\hline $\boldsymbol{B} \boldsymbol{S}_{\mathbf{2}}$ & 0.2 & 1 & 0.14 & 3 \\
\hline $\boldsymbol{B} \boldsymbol{S}_{\mathbf{3}}$ & 0.33 & 7 & 1 & 3 \\
\hline $\boldsymbol{B} \boldsymbol{S}_{\mathbf{4}}$ & 0.33 & 0.33 & 0.33 & 1 \\
\hline
\end{tabular}

\begin{tabular}{|c|c|c|c|c|}
\hline Expert 3 & $\boldsymbol{B} \boldsymbol{S}_{\mathbf{1}}$ & $\boldsymbol{B} \boldsymbol{S}_{\mathbf{2}}$ & $\boldsymbol{B} \boldsymbol{S}_{\mathbf{3}}$ & $\boldsymbol{B} \boldsymbol{S}_{\mathbf{4}}$ \\
\hline $\boldsymbol{B} \boldsymbol{S}_{\mathbf{1}}$ & 1 & 5 & 3 & 7 \\
\hline $\boldsymbol{B} \boldsymbol{S}_{\mathbf{2}}$ & 0.2 & 1 & 3 & 7 \\
\hline $\boldsymbol{B} \boldsymbol{S}_{\mathbf{3}}$ & 0.33 & 0.33 & 1 & 5 \\
\hline $\boldsymbol{B} \boldsymbol{S}_{\mathbf{4}}$ & 0.14 & 0.14 & 0.2 & 1 \\
\hline
\end{tabular}

\begin{tabular}{|c|c|c|c|c|}
\hline Expert 4 & $\boldsymbol{B} \boldsymbol{S}_{\mathbf{1}}$ & $\boldsymbol{B} \boldsymbol{S}_{\mathbf{2}}$ & $\boldsymbol{B} \boldsymbol{S}_{\mathbf{3}}$ & $\boldsymbol{B} \boldsymbol{S}_{\mathbf{4}}$ \\
\hline $\boldsymbol{B} \boldsymbol{S}_{\mathbf{1}}$ & 1 & 3 & 5 & 5 \\
\hline $\boldsymbol{B} \boldsymbol{S}_{\mathbf{2}}$ & 0.33 & 1 & 5 & 5 \\
\hline $\boldsymbol{B} \boldsymbol{S}_{\mathbf{3}}$ & 2 & 0.2 & 1 & 7 \\
\hline $\boldsymbol{B} \boldsymbol{S}_{\mathbf{4}}$ & 2 & 0.2 & 0.14 & 1 \\
\hline
\end{tabular}

\begin{tabular}{|c|c|c|c|c|}
\hline Expert 5 & $\boldsymbol{B} \boldsymbol{S}_{\mathbf{1}}$ & $\boldsymbol{B} \boldsymbol{S}_{\mathbf{2}}$ & $\boldsymbol{B} \boldsymbol{S}_{\mathbf{3}}$ & $\boldsymbol{B} \boldsymbol{S}_{\mathbf{4}}$ \\
\hline $\boldsymbol{B} \boldsymbol{S}_{\mathbf{1}}$ & 1 & 5 & 5 & 3 \\
\hline $\boldsymbol{B} \boldsymbol{S}_{\mathbf{2}}$ & 0.2 & 1 & 0.11 & 3 \\
\hline $\boldsymbol{B} \boldsymbol{S}_{\mathbf{3}}$ & 0.2 & 9 & 1 & 5 \\
\hline $\boldsymbol{B} \boldsymbol{S}_{\mathbf{4}}$ & 0.33 & 0.33 & 0.2 & 1 \\
\hline
\end{tabular}

\begin{tabular}{|c|c|c|c|c|}
\hline Expert 6 & $\boldsymbol{B} \boldsymbol{S}_{\mathbf{1}}$ & $\boldsymbol{B S _ { \mathbf { 2 } }}$ & $\boldsymbol{B} \boldsymbol{S}_{\mathbf{3}}$ & $\boldsymbol{B} \boldsymbol{S}_{\mathbf{4}}$ \\
\hline $\boldsymbol{B} \boldsymbol{S}_{\mathbf{1}}$ & 1 & 7 & 5 & 3 \\
\hline $\boldsymbol{B} \boldsymbol{S}_{\mathbf{2}}$ & 0.14 & 1 & 0.33 & 0.33 \\
\hline $\boldsymbol{B} \boldsymbol{S}_{\mathbf{3}}$ & 0.2 & 3 & 1 & 7 \\
\hline $\boldsymbol{B} \boldsymbol{S}_{\mathbf{4}}$ & 0.33 & 3 & 0.14 & 1 \\
\hline
\end{tabular}

\begin{tabular}{|c|c|c|c|c|}
\hline Expert 7 & $\boldsymbol{B} \boldsymbol{S}_{\mathbf{1}}$ & $\boldsymbol{B} \boldsymbol{S}_{\mathbf{2}}$ & $\boldsymbol{B} \boldsymbol{S}_{\mathbf{3}}$ & $\boldsymbol{B} \boldsymbol{S}_{\mathbf{4}}$ \\
\hline $\boldsymbol{B} \boldsymbol{S}_{\mathbf{1}}$ & 1 & 7 & 5 & 3 \\
\hline $\boldsymbol{B} \boldsymbol{S}_{\mathbf{2}}$ & 0.14 & 1 & 0.33 & 0.2 \\
\hline $\boldsymbol{B} \boldsymbol{S}_{\mathbf{3}}$ & 0.2 & 3 & 1 & 0.33 \\
\hline $\boldsymbol{B} \boldsymbol{S}_{\mathbf{4}}$ & 0.33 & 5 & 3 & 1 \\
\hline
\end{tabular}

\begin{tabular}{|c|c|c|c|c|}
\hline Expert 8 & $\boldsymbol{B} \boldsymbol{S}_{\mathbf{1}}$ & $\boldsymbol{B} \boldsymbol{S}_{\mathbf{2}}$ & $\boldsymbol{B} \boldsymbol{S}_{\mathbf{3}}$ & $\boldsymbol{B} \boldsymbol{S}_{\mathbf{4}}$ \\
\hline $\boldsymbol{B} \boldsymbol{S}_{\mathbf{1}}$ & 1 & 5 & 5 & 7 \\
\hline $\boldsymbol{B} \boldsymbol{S}_{\mathbf{2}}$ & 0.2 & 1 & 0.14 & 0.14 \\
\hline $\boldsymbol{B} \boldsymbol{S}_{\mathbf{3}}$ & 0.2 & 7 & 1 & 0.2 \\
\hline $\boldsymbol{B} \boldsymbol{S}_{\mathbf{4}}$ & 0.14 & 7 & 5 & 1 \\
\hline
\end{tabular}

\begin{tabular}{|c|c|c|c|c|}
\hline Expert 9 & $\boldsymbol{B} \boldsymbol{S}_{\mathbf{1}}$ & $\boldsymbol{B} \boldsymbol{S}_{\mathbf{2}}$ & $\boldsymbol{B} \boldsymbol{S}_{\mathbf{3}}$ & $\boldsymbol{B} \boldsymbol{S}_{\mathbf{4}}$ \\
\hline $\boldsymbol{B} \boldsymbol{S}_{\mathbf{1}}$ & 1 & 5 & 3 & 3 \\
\hline $\boldsymbol{B} \boldsymbol{S}_{\mathbf{2}}$ & 0.2 & 1 & 0.2 & 0.33 \\
\hline $\boldsymbol{B} \boldsymbol{S}_{\mathbf{3}}$ & 0.33 & 5 & 1 & 3 \\
\hline $\boldsymbol{B} \boldsymbol{S}_{\mathbf{4}}$ & 0.33 & 3 & 0.33 & 1 \\
\hline
\end{tabular}

\begin{tabular}{|c|c|c|c|c|}
\hline Expert 10 & $\boldsymbol{B} \boldsymbol{S}_{\mathbf{1}}$ & $\boldsymbol{B} \boldsymbol{S}_{\mathbf{2}}$ & $\boldsymbol{B} \boldsymbol{S}_{\mathbf{3}}$ & $\boldsymbol{B} \boldsymbol{S}_{\mathbf{4}}$ \\
\hline $\boldsymbol{B} \boldsymbol{S}_{\mathbf{1}}$ & 1 & 7 & 3 & 3 \\
\hline $\boldsymbol{B} \boldsymbol{S}_{\mathbf{2}}$ & 0.14 & 1 & 0.33 & 0.2 \\
\hline $\boldsymbol{B} \boldsymbol{S}_{\mathbf{3}}$ & 0.33 & 3 & 1 & 3 \\
\hline $\boldsymbol{B} \boldsymbol{S}_{\mathbf{4}}$ & 0.33 & 5 & 0.33 & 1 \\
\hline
\end{tabular}

Secondly, 10 experts' judgments in Table 3 are collaborated by the geometric mean and a pairwise comparison matrix $(A)$ is established. The results are given in Table 4. As an example, relative weight of the $B S_{1}$ over $B S_{2}$ is calculated by $(3 \times 5 \times 5 \times 3 \times 5 \times 7 \times 7 \times 5 \times 5 \times 7){ }^{(1 / 10)}=4.99$

Table 4. Collaboration of Expert Judgments on Business Strategies

\begin{tabular}{|l|c|c|c|c|}
\hline & $\boldsymbol{B} \boldsymbol{S}_{\mathbf{1}}$ & $\boldsymbol{B \boldsymbol { S } _ { \mathbf { 2 } }}$ & $\boldsymbol{B \boldsymbol { S } _ { \mathbf { 3 } }}$ & $\boldsymbol{B \boldsymbol { S } _ { \mathbf { 4 } }}$ \\
\hline $\boldsymbol{B} \boldsymbol{S}_{\mathbf{1}}$ & 1 & 4.99 & 4.08 & 3.94 \\
\hline $\boldsymbol{B} \boldsymbol{S}_{\mathbf{2}}$ & 0.20 & 1 & 0.39 & 0.72 \\
\hline $\boldsymbol{B} \boldsymbol{S}_{\mathbf{3}}$ & 0.31 & 2.55 & 1 & 2.62 \\
\hline $\boldsymbol{B} \boldsymbol{S}_{\mathbf{4}}$ & 0.32 & 1.37 & 0.38 & 1 \\
\hline
\end{tabular}

In order to find the weights of each business strategy, each entry of $A$ is divided by the sum of the related column and the average of each row (weight of the business strategy) is calculated. The results are presented in Table 5. 


\section{Table 5. Eigenvector and Weights of Business Strategies}

\begin{tabular}{|l|l|l|l|l|}
\hline & $\boldsymbol{B} \boldsymbol{S}_{\mathbf{1}}$ & $\boldsymbol{B S _ { \mathbf { 2 } }}$ & $\boldsymbol{B} \boldsymbol{S}_{\mathbf{3}}$ & $\boldsymbol{B S _ { 4 }}$ \\
\hline $\boldsymbol{B S}_{\mathbf{1}}$ & 0.55 & 0.50 & 0.70 & 0.48 \\
\hline $\boldsymbol{B S}_{\mathbf{2}}$ & 0.11 & 0.10 & 0.07 & 0.09 \\
\hline $\boldsymbol{B} \boldsymbol{S}_{\mathbf{3}}$ & 0.17 & 0.26 & 0.17 & 0.32 \\
\hline $\boldsymbol{B} \boldsymbol{S}_{\mathbf{4}}$ & 0.17 & 0.14 & 0.06 & 0.12 \\
\hline
\end{tabular}

\begin{tabular}{|c|}
\hline $\begin{array}{c}\text { Average of Rows } \\
\text { (Weights of Business Strategies) }\end{array}$ \\
\hline 0.56 \\
\hline 0.09 \\
\hline 0.23 \\
\hline 0.12 \\
\hline
\end{tabular}

As seen in Table 5, establishing efficient decision support systems $\left(B S_{1}\right)$ is the most important business strategy with its weight $56 \%$. Providing modern infrastructures $\left(B S_{3}\right)$ has also high weight, $23 \%$. Integrating with the international financial structure $\left(B S_{4}\right)$ and developing agile processes $\left(B S_{2}\right)$ have low significance by $12 \%$ and $9 \%$, respectively.

Similar to business strategies, IT strategies were also evaluated by the experts in pairs. For this purpose, expert judgments on six IT strategies were collected with respect to each business strategy, separately. Thus, relative weights of IT strategies were found by aligning business and IT strategies. As a result of expert judgments, relative weights of IT strategies with respect to business strategies are given in Table 6 .

Table 6. Collaboration of Expert Judgments on IT Strategies in Terms of Business Strategies

\begin{tabular}{|l|c|c|c|c|}
\hline & According to $\boldsymbol{B} \boldsymbol{S}_{\mathbf{1}}$ & According to $\boldsymbol{B S}_{\mathbf{2}}$ & According to $\boldsymbol{B S}_{\mathbf{3}}$ & According to $\boldsymbol{B S}_{\mathbf{4}}$ \\
\hline $\boldsymbol{I} \boldsymbol{T S}_{\mathbf{1}}$ & 0.27 & 0.09 & 0.13 & 0.12 \\
\hline $\boldsymbol{I} \boldsymbol{T S}_{\mathbf{2}}$ & 0.22 & 0.24 & 0.10 & 0.08 \\
\hline $\boldsymbol{I T S}_{\mathbf{3}}$ & 0.06 & 0.12 & 0.36 & 0.16 \\
\hline $\boldsymbol{I T S}_{\mathbf{4}}$ & 0.18 & 0.10 & 0.13 & 0.35 \\
\hline $\boldsymbol{I T S}_{\mathbf{5}}$ & 0.16 & 0.28 & 0.10 & 0.16 \\
\hline $\boldsymbol{I T S}_{\mathbf{6}}$ & 0.11 & 0.17 & 0.18 & 0.13 \\
\hline
\end{tabular}

Final weight of each IT strategy is obtained by multiplying matrix given in Table 6 and the vector representing the importance of the related business strategies in Table 5. As an example, the weight of ITS $_{1}$ is found by $0.27 \times 0.56+0.09 \times 0.09+0.13 \times 0.23+0.12 \times 0.12=0.20$. Final weights of six IT strategies are given in Table 7

Table 7. Weights of IT Strategies

\begin{tabular}{|c|c|}
\hline & Weights \\
\hline ITS $_{\mathbf{1}}$ & 0.20 \\
\hline $\boldsymbol{I T S}_{\mathbf{2}}$ & 0.18 \\
\hline $\boldsymbol{I T S}_{\mathbf{3}}$ & 0.15 \\
\hline $\boldsymbol{I T S}_{\mathbf{4}}$ & 0.18 \\
\hline $\boldsymbol{I T S}_{\mathbf{5}}$ & 0.16 \\
\hline $\boldsymbol{I T S}_{\mathbf{6}}$ & 0.13 \\
\hline
\end{tabular}

According to the results in Table 7, transformation in the customer oriented digital channel $\left(I T S_{1}\right)$ is the most important IT strategy with its weight $20 \%$. This result is found consistent and acceptable as a natural consequence of technological developments in alternative distribution channels in banking. Customer oriented application development $\left(I T S_{2}\right)$ and integration with the other organizations $\left(I T S_{4}\right)$ are the second best IT strategies by their weights, $18 \%$. Other IT strategies $\left(I T S_{3}, I T S_{5}, I T S_{6}\right)$ are also important with their importance values, $15 \%, 16 \%$, and $13 \%$, respectively.

Similar to business and IT strategies, six service areas were also assessed by the experts in pairs and in terms of each IT strategy. As a result, relative weights of service areas which were found by aligning IT strategies and service areas are presented in Table 8. 
Table 8. Collaboration of Expert Judgments on Service Areas in Terms of IT Strategies

\begin{tabular}{|l|c|c|c|c|c|c|}
\hline & $\begin{array}{c}\text { According to } \\
\boldsymbol{I T S}_{\mathbf{1}}\end{array}$ & According to $\boldsymbol{I T S}_{\mathbf{2}}$ & According to $\boldsymbol{I T S}_{\mathbf{3}}$ & According to $\boldsymbol{I T S}_{\mathbf{4}}$ & According to $\boldsymbol{I T S}_{\mathbf{5}}$ & According to $\boldsymbol{I T S}_{\mathbf{6}}$ \\
\hline $\boldsymbol{S A}_{\mathbf{1}}$ & 0.45 & 0.13 & 0.10 & 0.16 & 0.09 & 0.12 \\
\hline $\boldsymbol{S A}_{\mathbf{2}}$ & 0.08 & 0.10 & 0.12 & 0.08 & 0.15 & 0.09 \\
\hline $\boldsymbol{S A}_{\mathbf{3}}$ & 0.13 & 0.15 & 0.15 & 0.21 & 0.17 & 0.17 \\
\hline $\boldsymbol{S A}_{\mathbf{4}}$ & 0.18 & 0.26 & 0.22 & 0.30 & 0.28 & 0.21 \\
\hline $\boldsymbol{S A}_{\mathbf{5}}$ & 0.06 & 0.15 & 0.37 & 0.11 & 0.10 & 0.34 \\
\hline $\boldsymbol{S A}_{\mathbf{6}}$ & 0.10 & 0.21 & 0.04 & 0.14 & 0.21 & 0.07 \\
\hline
\end{tabular}

Final weights of service areas are obtained by multiplying matrix given in Table 8 and the vector showing the importance of IT strategies in Table 7. As an example, the importance of $\boldsymbol{S A}_{\mathbf{1}}$ is found by $0.45 \times 0.20+$ $0.13 \times 0.18+0.10 \times 0.15+0.16 \times 0.18+0.09 \times 0.16+0.12 \times 0.13=0.19$. Finally, weights of six service areas are given in Table 9.

\section{Table 9. Weights of Service Areas}

\begin{tabular}{|c|c|}
\hline & Weights \\
\hline $\boldsymbol{S A}_{\mathbf{1}}$ & 0.19 \\
\hline $\boldsymbol{S A}_{\mathbf{2}}$ & 0.10 \\
\hline $\boldsymbol{S A}_{\mathbf{3}}$ & 0.16 \\
\hline $\boldsymbol{S A}_{\mathbf{4}}$ & 0.24 \\
\hline $\boldsymbol{S A}_{\mathbf{5}}$ & 0.18 \\
\hline $\boldsymbol{S A}_{\mathbf{6}}$ & 0.13 \\
\hline
\end{tabular}

As seen in Table 9, analytic applications $\left(\mathrm{SA}_{4}\right)$ are the most important service areas by $24 \%$ weight. According to the experts, this is very accurate result based on the rapid developments and high requirements in analytic applications for banks (i.e., Customer Relationship Management - CRM, big data analytic, data warehouse, business intelligence, data mining, enterprise integration etc.). Channels $\left(S A_{1}\right)$ are the second important service areas by $19 \%$ importance. This is also acceptable since IT companies of banks have to invest in different channels (i.e., Automated Teller Machines - ATM, Point of Sales - POS, internet, web, mobile, e-mail, social network, etc.) in order to get competitive advantage in the market. Moreover, system infrastructure, data center and security $\left(S A_{5}\right)$ applications are fundamental service areas by $18 \%$ weight. This means that, the company has to make investment in backup and restore, server operating systems, Local Area Network - LAN, Wide Area Network - WAN, database for system infrastructure; cloud and virtualization for data center technologies; data, network, system, application and physical security for safeness. Furthermore, external systems and business applications $\left(\mathrm{SA}_{3}\right)$ have $16 \%$ weight meaning the company has also allocate its resources to the Swift, Western Union, payment organizations for external systems and campaign management, credit applications and credit cards etc. for business. Supporting applications $\left(S A_{6}\right)$ have $13 \%$ weight with respect to IT strategies, therefore, human resources, process-project-risk-procurement management functions are also necessary expenditure items for the company. Finally, automation in branches $\left(\mathrm{SA}_{2}\right)$ is the least important service area by $10 \%$ which means investing in printer, fax, server, network, money counter machine etc. to be used in the branches can be postponed in comparison with the other service areas in terms of business and IT strategies. This is also found acceptable by the senior managers of the IT company and bank due to the decrease in the popularity of the branches beside alternative distribution channels.

\section{CONCLUSIONS AND FURTHER RESEARCH}

In this paper, authors propose a method to align business-IT strategies and IT strategies-service areas. It is apparent that, there is not an internationally accepted method to be used in order to align strategies and evaluate the strategic fit in IT industry. Therefore, finding ways of using IT to support the business strategy has become important for both researchers and practitioners. Moreover, since most organizations implement IT functions just to operate, the solution for the problem about allocating the IT budget to the 
Journal of Global Strategic Management | V. 12 | N. 1 | 2018-June | isma.info | 005-016 | DOI: 10.20460/JGSM.2018.256

most yielding service areas is not solved yet. For this reason, authors propose AHP method to align the strategies, find their relative importance weights, and determine the rate of investment for each service area.

AHP is an analytical method based on experts' opinion stated on a problem decomposed into a hierarchy. Relative assessments on the criteria and alternatives are implied according to the hierarchical relations. It is clear that, AHP is an efficient method for the strategic alignment and budget allocation problem since it integrates analytical methods and expert judgments. In this study, firstly, authors propose business-IT strategies and IT service areas by the help of the senior managers working in a Turkish bank and its IT company depending on the technological improvements and benchmark studies. Subsequently, authors obtain the weights of the strategies and service areas by expert judgment using AHP. Authors experimentally demonstrate that establishing efficient decision support systems $\left(B S_{1}\right)$ is the most fundamental business strategy while providing modern infrastructures $\left(B S_{3}\right)$ is also important. Moreover, authors find the transformation in the customer oriented digital channel $\left(I T S_{1}\right)$ as the most important IT strategy, customer oriented application development $\left(I T S_{2}\right)$ and integration with the other organizations $\left(I T S_{4}\right)$ as the second best IT strategies. Finally, the results of the study show that analytic applications $\left(\mathrm{SA}_{4}\right)$ are the most important service area in terms of business and IT strategies. In other words, the bank has to invest in CRM, big data analytic, data warehouse, business intelligence, data mining etc. Similarly, investing in ATM, POS, internet, mobile is also inevitable since channels $\left(S A_{1}\right)$ are the second important service areas. The outcomes of the study are also approved by both the senior managers in the bank and IT company depending on the recent developments in the banking and IT industry.

Further studies may involve the improvement of a mathematical model based on weights obtained by AHP and considering specific constraints (i.e., budget, time). 

REFERENCES

Badri, M. A. (2001), A Combined AHP - GP Model for Quality Control Systems. International Journal of Production Economics, 72, 27 - 40.

Baets, W. (1992), Aligning Information Systems with Business Strategy. Journal of Strategic Information Systems, 1(4), 205-213.

Bergeron, F., Raymond, L., and Rivard, S. (2004), Ideal Patterns of Strategic Alignment and Business Performance. Information and Management, 41(8), 1003-1020.

Boaden, R. J. (2006), Leadership Development: Does it Make a Difference? Leadership and Organization Development Journal, 27(1/2), 5-27.

Brady, T., and Targett, D. (1996), "Strategic information systems in the banking sector: Holy grail or poison chalice. Technology Analysis and Strategic Management, 7(4), 387 - 406.

Brodbeck, N., Rigoni, E., and Hoppen, N. (2009), Strategic Alignment Maturity Between Business and Information Technology in Southern Brazil. Journal of Global Information Technology Management, 12(2), 5-32.

Burgelman, R., and Doz, Y. (2001), The Power of Strategic Integration. Sloan Management Review, 42(3), 28-38.

Chan, Y., and Reich, B. (2007), IT Alignment: What Have We Learned. Journal of Information Technology, 22(4), 297-315.

Chan, Y., Sabherwal, R., and Thatcher, J. (2006), Antecedents and Outcomes of Strategic IS Alignment: An Empirical Investigation. IEEE Transactions on Engineering Management, 53 (1), 27- 47.

Chiang, I. R., and Nunez, M. A. (2013), Strategic Alignment and Value Maximization for IT Project Portfolios. Information Technology and Management, 14, 143-157.

Coltman, T., Sharma, R., and Tallon, P. (2013), Strategic IT Alignment: Twenty Five Years On. Journal of Information Technology, 30 (2), 91 - 100.

DeLone, W. H. and McLean, E. R. (2002), Information Systems Success Revisited. Proceedings of the 35th Hawaiian International Conference on Systems Sciences (HICSS-35'02).

El Haji, E., Azmani, A., and El Harzli, M. (2017), Using AHP Method for Educational and Vocational Guidance. International Journal of Information Technology and Computer Science, 1, 9-17.

Gordon, S., Tarafdar, M., Cook, R., Maksimoski, R., and Rogowitz, B. (2008), Improving the Front End of Innovation with Information Technology. Research Technology Management, 51(3), 50-58.

Henderson, J. and Venkatraman, N. (1993), Strategic Alignment: Leveraging Information Technology for Transforming Organizations. IBM Systems Journal. 32(1), 472-484.

Henderson, J.C., and Venkatraman, N. (1999), Strategic Alignment: Leveraging Information Technology for Transforming Organizations. IBM Systems Journal, 38 (2and3), 472-484.

Huang, L. (2009), The Contingent Role of Innovation Between IT Management Sophistication and Strategic Alignment. Journal of Global Information Management, 17, 60-92.

Kanellis, P., Lycett, M., and Paul, R. (1999), Evaluating Business Information Systems Fit: from Concept to Practical Application. European Journal of Information Systems, 8(1), 65 - 76.

Karim, R., and Karmaker, C.L. (2016), Machine Selection by AHP and TOPSIS Methods. American Journal of Industrial Engineering, 4(1), 7-13.

Kearns, G.S., and Lederer, A.L. (2003), A Resource-Based View of Strategic IT Alignment: How Knowledge Sharing Creates Competitive Advantage. Decision Sciences, 34 (1), 1-29.

Kutlu, B., Bozanta, A., Ates, E., Erdogan, S., Gokay, O., and Kan, N. (2014), Project Management Software Selection Using Analytic Hierarchy Process Method. International Journal of Applied Science and Technology, 4(6), 113-119.

Labovitz, G., and Rosansky, V. (1997), The Power of Alignment: How Great Companies Stay Centered and Accomplish Extraordinary Things. New York: John Wiley and Sons. 
Journal of Global Strategic Management | V. 12 | N. 1 | 2018-June | isma.info | 005-016 | DOI: 10.20460/JGSM.2018.256

Lankhorst, M. (2005), Enterprise Architecture at Work: Modelling, Communication and Analysis. Berlin Heidelberg:Springer-Verlag.

Longaray, A.A., Gois, J.D.R., and Munhoz, P.R.S. (2015), Proposal for Using AHP Method to Evaluate the Quality of Services Provided by Outsourced Companies. Procedia Computer Science Volume, 55, 715-724.

Luftman J. (2001), Business-IT Alignment Maturity” in R. Papp, Strategic Information Technology: Opportunities for Competitive Advantage. Longon: Idea Group Publishing: 107.

Malczewski, J. (1999), GIS and Multicriteria Decision Making. New York: John Wiley and Sons.

Masa'deh, R. (2012), The Impact of Management Information Systems (MIS) on Quality Assurance (QA): A Case Study in Jordan. International Journal of Information, Business and Management, 4 (2), 93-110.

Miller, J. (1993), Measuring and Aligning Information Systems with the Organization. Information and Management, 25 (4), 217-228.

Papp, R. (1995), Determinants of Strategically Aligned Organizations: A Multi-Industry, Multiperspective Analysis, Stevens Institute of Technology, Hoboken, New Jersey.

Reich, B., and Benbasat, I. (1996), Measuring the Linkage between Business and Information Technology Objectives. MIS Quarterly, 20 (1), 55-81

Saaty, T.L. (1980), The Analytic Hierarchy Process. McGraw - Hill, Inc.

Saaty, T. L. (1990), How to Make a Decision: The Analytic Hierarchy Process. European Journal of Operational Research, 48, 9-26.

Sabherwal, R. Hirschheim, R. and Goles, T. (2001), The Dynamics of Alignment: Insights from a Punctuated Equilibrium Model. Organization Science, 12 (2), 179-197.

Sambamurthy, V., Bharadwaj, A., and Grover, V. (2003), Shaping Agility through Digital Options: Reconceptualizing the Role of Information Technology in Contemporary Firms. MIS Quarterly, Volume 27(2), 237-263.

Tarhini, A., Hone, K., and Liu, X. (2013), Factors Affecting Students' Acceptance of E-learning Environments in Developing Countries: A Structural Equation Modeling Approach. International Journal of Information and Education Technology, 3(1), 54-59.

Tasci, M.E., Gorener, A. (2016), Evaluating the Strategies of Medical Tourism Sector Through AHP and Moora in a SWOT Framework. Journal of Global Strategic Management, 10(2), 15 - 30.

Thompson, A. A., Strickland, A. J., and Gamble, J. E. (2007), Crafting and Executing Strategy. (15th ed.) Boston: McGraw-Hill Irwin.

TOGAF Version 9.1.(2011), The Open Group, Van Haren Publishing.

Torres, I.T., Jover, A.J.V., and Morales, V.J.G. (2012), Sources of Strategic Fit in High-Tech Firms. Technology Analysis and Strategic Management, 24(10), 997 - 1011.

Wagner, H.T., Beimborn, D., and Weitzel, T. (2014), How Social Capital among Information Technology and Business Units Drives Operational Alignment and IT Business Value. Journal of Management Information Systems, 31(1), 241-272.

Walter, J., Kellermanns, F., and Floyd, S. (2013), Strategic Alignment: A Missing Link in the Relationship between Strategic Consensus and Organizational Performance. Strategic Organization, 11 (3), 304-328.

Wang, J.S., Liu, C.H., and Shyu, J.Z. (2013), Biometrics Technology Evaluating and Selecting Model Building. Technology Analysis and Strategic Management, 25(9), 1067 - 1083.

Yoon, Y. K. (2005), An Evaluation System for IT Outsourcing Customer Satisfaction Using the Analytic Hierarchy Process. Journal of Global Information Management, 13(4), 53-75. 
Journal of Global Strategic Management | V. 12 | N. 1 | 2018-June | isma.info | 005-016 | DOI: 10.20460/JGSM.2018.256 Zachman. J. A. (1987), A Framework for Information Systems Architecture. IBM Systems Journal, 26(3), 276-292.

Zachman, J. A. (2003), The Zachman Framework for Enterprise Architecture: Primer for Enterprise Engineering and Manufacturing. Zachman International.

Zahra, S., and Covin, G. (1993), Business Strategy, Technology Policy and Firm Performance. Strategic Management Journal, 14(6), 451 - 478. 